\title{
Front Matter: Volume 11082
}

, "Front Matter: Volume 11082," Proc. SPIE 11082, Plasmonics: Design, Materials, Fabrication, Characterization, and Applications XVII, 1108201 (30 September 2019); doi: 10.1117/12.2552386

SPIE Event: SPIE Nanoscience + Engineering, 2019, San Diego, California, United SPIE. States 


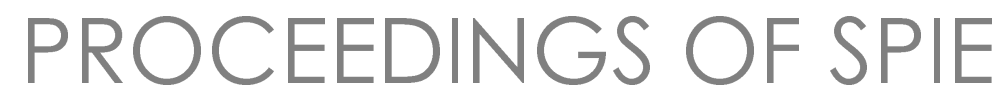

\title{
Plasmonics: Design, Materials, Fabrication, Characterization, and Applications XVII
}

\author{
Din Ping Tsai \\ Takuo Tanaka \\ Editors
}

11-15 August 2019

San Diego, California, United States

Sponsored and Published by

SPIE 
The papers in this volume were part of the technical conference cited on the cover and title page. Papers were selected and subject to review by the editors and conference program committee. Some conference presentations may not be available for publication. Additional papers and presentation recordings may be available online in the SPIE Digital Library at SPIEDigitallibrary.org.

The papers reflect the work and thoughts of the authors and are published herein as submitted. The publisher is not responsible for the validity of the information or for any outcomes resulting from reliance thereon.

Please use the following format to cite material from these proceedings:

Author(s), 'Title of Paper," in Plasmonics: Design, Materials, Fabrication, Characterization, and Applications XVII, edited by Din Ping Tsai, Takuo Tanaka, Proceedings of SPIE Vol. 11082 (SPIE, Bellingham, WA, 2019) Seven-digit Article CID Number.

ISSN: 0277-786X

ISSN: 1996-756X (electronic)

ISBN: 9781510628571

ISBN: 9781510628588 (electronic)

Published by

SPIE

P.O. Box 10, Bellingham, Washington 98227-0010 USA

Telephone +1 3606763290 (Pacific Time) · Fax +1 3606471445

SPIE.org

Copyright @ 2019, Society of Photo-Optical Instrumentation Engineers.

Copying of material in this book for internal or personal use, or for the internal or personal use of specific clients, beyond the fair use provisions granted by the U.S. Copyright Law is authorized by SPIE subject to payment of copying fees. The Transactional Reporting Service base fee for this volume is $\$ 21.00$ per article (or portion thereof), which should be paid directly to the Copyright Clearance Center (CCC), 222 Rosewood Drive, Danvers, MA 01923. Payment may also be made electronically through CCC Online at copyright.com. Other copying for republication, resale, advertising or promotion, or any form of systematic or multiple reproduction of any material in this book is prohibited except with permission in writing from the publisher. The CCC fee code is 0277$786 \times / 19 / \$ 21.00$.

Printed in the United States of America by Curran Associates, Inc., under license from SPIE.

Publication of record for individual papers is online in the SPIE Digital Library.

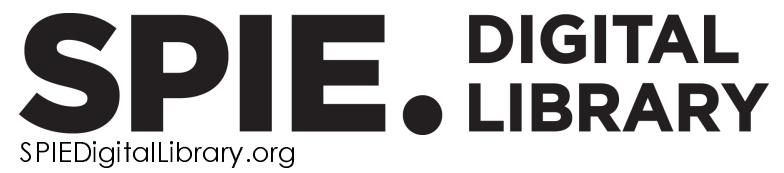

Paper Numbering: Proceedings of SPIE follow an e-First publication model. A unique citation identifier (CID) number is assigned to each article at the time of publication. Utilization of CIDs allows articles to be fully citable as soon as they are published online, and connects the same identifier to all online and print versions of the publication. SPIE uses a seven-digit CID article numbering system structured as follows:

- The first five digits correspond to the SPIE volume number.

- The last two digits indicate publication order within the volume using a Base 36 numbering system employing both numerals and letters. These two-number sets start with $00,01,02,03,04$, 05, 06, 07, 08, 09, OA, OB ... 0Z, followed by 10-1Z, 20-2Z, etc. The CID Number appears on each page of the manuscript. 


\title{
Contents
}

\author{
vii Authors \\ ix Conference Committee \\ xiii Introduction
}

PLASMONIC LASER

11082 OL Plasmonic nanolasers based on graphene-insulator-metal platform (Invited Paper) [1 1082-20]

PLASMONIC MATERIALS AND NANOSTRUCTURES

11082 OP Rainbow light trapping in ultrathin plasmonic nanogratings [1 1082-24]

THERMAL PLASMONICS

11082 OS Thermoplasmonics for investigation of microbubble dynamics in degassed water (Invited Paper) [1 1082-27]

\section{NONLINEAR}

11082 OW Amplifying conversion efficiencies of SP-enhanced SHG from Ag surface with nonlinear optical polymer films [1 1082-31]

PLASMONIC SENSING I

1108215 In vivo detection of microRNA within plants using plasmonic nanosensors [1 1082-43]

PLASMONIC SENSING ॥

11082 1D Plasmonic sensing of hydrogen in Pd nano-hole arrays [1 1082-50] 
FUNDAMENTALS OF PLASMONICS III

$110821 \mathrm{H} \quad$ Investigating electromagnetic field enhancements from gold nanostructured arrays for plasmon enhanced fluorescence [1 1082-54]

\section{PLASMONIC APPLICATIONS II}

$110821 \mathrm{~K} \quad$ Self-organized metasurfaces enabling plasmon hybridization [1 1082-58]

\section{POSTERS-WEDNESDAY}

11082 1P Surface plasmon-polariton waves guided by reciprocal, uniaxially chiral, bianisotropic material [1 1082-63]

11082 is Enhancement of optical near field by bowtie nanoantenna with V-structured hole [1 1082-67]

$110821 \mathrm{IT} \quad$ Semiconductor-based nanostructures for spectral filtering [1 1082-68]

$110821 \mathrm{~L} \quad$ Local field enhancement by using composite grating with nanogaps [1 1082-70]

$110821 \mathrm{~V} \quad$ Development of color 8K photo printing with plasmonic pixels [1 1082-71]

11082 1X Plasmonic-induced transparency based on MIM waveguide achieved by the structure including a rectangular ring and a rectangular strip [1 1082-73]

$110821 Y \quad$ Tunable dual-band metamaterial absorber based on cross-shaped graphene [11082-74]

$1108224 \quad$ Embedded surface plasmon resonant disc arrays for improved MWIR sensitivity and increased operating temperature of PbSe photoconductive detectors [1 1082-81]

1108228 Multiple annealing based photonic tunability for enhanced photo-response of AuGe nanoparticles [1 1082-85]

1108229 Design of arrow shaped nanoantenna for electric field enhancement [1 1082-87]

11082 2A Chemical analysis of air pollutant particulate matters based on surface enhanced Raman spectroscopy (SERS) [1 1082-88]

11082 2C Narrowband polarization-dependent fractal based plasmonic absorbers [1 1082-90] 
$110822 \mathrm{H} \quad$ Effect of silver nanoparticles on the luminescence spectral characteristics of rare-earth ion doped sodium borate glasses [1 1082-96]

1108221 The influence of the fabrication developing time on plasmonic bowtie nanoantenna metastructures [1 1082-97]

$11082 \mathrm{~L}$ Inverse molecular sentinel-integrated fiber sensor for direct detection of miRNA targets [1 1082-100]

$110822 \mathrm{~N}$ Analysis of graphene and sulfide coated surface plasmon resonance biosensors [1 1082-102]

11082 2W Synthesis, characterization, and computational modeling of polyelectrolyte-coated plasmonic gold nanorods for photothermal heating studies [1 1082-113] 
Proc. of SPIE Vol. 11082 1108201-6 Downloaded From: https://www.spiedigitallibrary.org/conference-proceedings-of-spie on 26 Apr 2023
Terms of Use: https://www.spiedigitallibrary.org/terms-of-use 


\section{Authors}

Numbers in the index correspond to the last two digits of the seven-digit citation identifier (CID) article numbering system used in Proceedings of SPIE. The first five digits reflect the volume number. Base 36 numbering is employed for the last two digits and indicates the order of articles within the volume. Numbers start with 00, 01, 02, 03, 04, 05, 06, 07, 08, 09, OA, OB...0Z, followed by 10-1Z, 20-2Z, etc.

Ahn, Yun, 2A

Barelli, M., $1 \mathrm{~K}$

Boyanov, Maxim I., 15

Buatier de Mongeot, F., $1 \mathrm{~K}$

Campbell, Caroline, 21

Casey, Abigail, 2l

Cerutti, Laurent, $1 \mathrm{~T}$

Chakrabarti, Subhananda, 28

Chavan, Vinayak, 28

Chiba, T., IV

Crawford, Bridget M., 15, 2L

Cupil-Garcia, Vanessa, 2L

Della Valle, G., IK

Dixon, Katelyn, OP

Drobitch, Justine, 21

Faryad, Muhammad, IP

Feng, He, 1S, 1U, 1X, 1Y

Fomra, Dhruv, 2l

Ganguly, Samiran, 24

Giordano, M. C., 1K

Gomes de Souza, Igor Leonardo, 2C

González-Posada Flores, Fernando, $1 T$

Grayer, Justin, 24

Haïdar, Riad, $1 T$

Inami, W., OW

Jiao, Kunpeng, 1S, IU, IY

Jiao, Lipeng, is

Jung, Taeyoung, 2A

Kalra, Yogita, 29

Kawata, Y., OW

Kemner, Kenneth M., 15

Kherani, Nazir P., OP

Kikuchi, K., OW

Kim, Eun-Ah, 2A

Kim, Hyun Woo, 2A

Kim, Jongwoo, 2A

Kim, Jungwoo, 2A

Kishor, Kamal, 29

Kitamura, M., $1 \mathrm{~V}$

Kong, Weijin, 1S, 1U, 1X, 1Y

Kumar, Samir, OS

Large, Nicolas, 2W

Larsen, George Keefe, ID

Lee, Jeong Seop, 2A

Liggins, Kristopher, $2 \mathrm{H}$

Liu, Yunpeng, $1 X$

Lopez, Priscilla, 2W

Lu, Tien-Chang, $\mathrm{OL}$

Luong, Hoang Mai, ID
Maës, Clément, $1 T$

Marlow, Emma L., $1 \mathrm{H}$

Matsuura, Naomi, OP

Mayer, Kathryn, 2W

Mazzanti, A., $1 \mathrm{~K}$

Mochizuki, K., OW

Mondal, Shubham, 28

Montazeri, Arthur, OP

Murphy, Antony P., 1H

Nam, Sang Hwan, 2A

Namura, Kyoko, OS

Nguyen, Tho Duc, 1D

Okai, Shunsuke, OS

Oliveira de Jesus, Priscila, 2N

Ono, A., OW

Park, Hyeong-Ryeol, 2A

Paul, Sritoma, 28

Pei, Zhen-Ming, 15

Pham, Minh Thien, 1D

Pollard, Robert J., 1H

Ran, Yang, $2 \mathrm{~L}$

Ranga, Ritika, 29

Rawool, Harshal, 28

Reddy, B. Rami, 2H

Rodriguez-Esquerre, Vitaly Felix, 2C, 2N

Shayegannia, Moein, OP

Shimada, Yusaku, OS

Shin, Hyeon Ho, 2A

Strobbia, Pietro, 15, 2L

Sugita, A., OW

Suh, Yung Doug, 2A

Sun, Tai-Ping, 15, 2L

Suzuki, Motofumi, OS

Takahara, J., IV

Takanokura, T., IV

Taliercio, Thierry, $1 \mathrm{~T}$

Triplett, Gregory, 21

Tyagi, Lavi, 28

Ueba, Y., 1V

Vincent, Grégory, $1 \mathrm{~T}$

Vo-Dinh, Tuan, 15, 2L

Wang, Hsin-Neng, 15, 2L

Wu, Di, 1U, 1Y

Xia, Feng, 1S, 1U, 1X, 1Y

$X U$, Zixuan, 1S, 1U, 1X, 1Y

Yamamoto, M., IV

Yoo, Sung-Shik, 24

Yu, Seong-Cho, 2A 
Yun, Maojin, 1S, 1U, 1X, 1Y

Zentella, Rodolfo, 15, 2L

Proc. of SPIE Vol. 11082 1108201-8

Downloaded From: https://www.spiedigitallibrary.org/conference-proceedings-of-spie on 26 Apr 2023 Terms of Use: https://www.spiedigitallibrary.org/terms-of-use 


\section{Conference Committee}

Symposium Chairs

Halina Rubinsztein-Dunlop, The University of Queensland (Australia)

Mark L. Brongersma, Geballe Laboratory for Advanced Materials

(GLAM) (United States) and Stanford University (United States)

Symposium Co-chairs

Reuven Gordon, University of Victoria (Canada)

Natalia M. Litchinitser, Duke University (United States)

Conference Chairs

Din Ping Tsai, National Taiwan University (Taiwan)

Takuo Tanaka, RIKEN Center for Advanced Photonics (Japan)

Conference Program Committee

Martin Aeschlimann, Technische Universität Kaiserslautern (Germany)

Harry A. Atwater Jr., California Institute of Technology (United States)

David J. Bergman, Tel Aviv University (Israel)

Che Ting Chan, Hong Kong University of Science and Technology (Hong Kong, China)

Yun-Chorng Chang, Academia Sinica (Taiwan)

Harald W. Giessen, Universität Stuttgart (Germany)

Naomi J. Halas, Rice University (United States)

Martti Kauranen, Tampere University of Technology (Finland)

Dai-Sik Kim, Seoul National University (Korea, Republic of)

Wakana Kubo, Tokyo University of Agriculture and Technology (Japan)

Laurens K. Kuipers, FOM Institute for Atomic and Molecular Physics (Netherlands)

Mikhail Lapine, The University of Sydney (Australia)

Ai Qun Liu, Nanyang Technological University (Singapore)

Yu-Jung Lu, National Taiwan University (Taiwan)

Olivier J. F. Martin, Ecole Polytechnique Fédérale de Lausanne (Switzerland)

Peter Nordlander, Rice University (United States)

George C. Schatz, Northwestern University (United States)

Tigran V. Shahbazyan, Jackson State University (United States)

Vladimir M. Shalaev, Purdue University (United States)

Gennady B. Shvets, Institute for Fusion Studies (United States) 
Niek F. van Hulst, ICFO - Institut de Ciències Fotòniques (Spain)

Prabhat Verma, Osaka University (Japan)

Hongxing $\mathbf{X u}$, Wuhan University (China)

Nikolay I. Zheludev, Optoelectronics Research Centre

(United Kingdom) and Nanyang Technological University

(Singapore)

\section{Session Chairs}

1 Keynote Session

Mark L. Brongersma, Geballe Laboratory for Advanced Materials (GLAM) (United States) and Stanford University (United States)

2 Fundamentals of Plasmonics I

Mark L. Brongersma, Geballe Laboratory for Advanced Materials (GLAM) (United States) and Stanford University (United States)

3 Characterization for Plasmonics

Koichi Okamoto, Osaka Prefecture University (Japan)

4 Fundamentals of Plasmonics II

David J. Norris, ETH Zurich (Switzerland)

$5 \quad$ Radiation Engineering

Hui Cao, Yale University (United States)

6 Plasmonic Vortices

Pin Chieh Wu, National Cheng Kung University (Taiwan)

7 Active Control

Keiji Sasaki, Hokkaido University (Japan)

8 Plasmonic Laser

Yukina Takahashi, Kyushu University (Japan)

9 Plasmonic Materials and Nanostructures

Yu-Jung Lu, Research Center for Applied Sciences - Academia Sinica (Taiwan)

10 Thermal Plasmonics

Hui-Hsin Hsiao, National Taiwan Normal University (Taiwan) 
11 Nonlinear

Wakana Kubo, Tokyo University of Agriculture and Technology (Japan)

12 Plasmonic Materials and Nanostructures

Laurens K. Kuipers, Kavli Institute of Nanoscience Delft (Netherlands)

13 Chiral Plasmonics

Yun-Chorng Chang, Research Center for Applied Sciences Academia Sinica (Taiwan)

14 Plasmonic Sensing I

Humeyra Caglayan, Tampere University (Finland)

15 Plasmonic Applications I

Valeria Rodionova, Immanuel Kant Baltic Federal University (Russian Federation)

16 Plasmonic Sensing II

Kuo-Ping Chen, National Chiao Tung University (Taiwan)

17 Fundamentals of Plasmonics III

Keiko Tawa, Kwansei Gakuin University (Japan)

18 Plasmonic Applications II

Zouheir Sekkat, Moroccan Foundation for Advanced Science, Innovation and Research (Morocco)

19 Plasmonic Applications III

Prabhat Verma, Osaka University (Japan) 
Proc. of SPIE Vol. 11082 1108201-12

Downloaded From: https://www.spiedigitallibrary.org/conference-proceedings-of-spie on 26 Apr 2023 Terms of Use: https://www.spiedigitallibrary.org/terms-of-use 


\section{Introduction}

This proceedings volume includes papers presented at the 2019 SPIE Optics + Photonics conference on Plasmonics: Design, Materials, Fabrication, Characterization, and Applications XVII held in San Diego, California, 11-15 August 2019. The aim of the conference was to bring together specialists from diverse research areas and to provide a forum for the exchange of information on the latest progress of plasmonics.

The conference was divided into 19 sessions, covering a variety of topics related to plasmonics. In the first keynote session, the paper presented the insight of modal strong coupling and its application to photochemical reactions.

The second session explored the topic of fundamentals of plasmonics, such as tunable plasmonics for wide wavelength range including deep UV using metal nano-hemisphere on mirror, and topological nodal-line state in silicon fcc photonic crystal.

The third session presentations discussed characterization for plasmonics: superresolved single molecule lifetime microscopy with large field of view and EELS studies of active plasmonic devices.

Fundamentals of plasmonics was featured in the fourth session, including spatiotemporal lasing dynamics in wave-chaotic and disordered cavities, complete coupling from a single photon to an ultraconfined plasmon, plasmonic metasurfaces with tunable gap and collective SPR modes, and electron cyclotron motion excited surface plasmon and radiation on semiconductor thin film.

Session five papers related to radiation engineering such as quantum strong coupling in an oligonucleotide-guided nanocavity, hybrid plasmonic nanosystem with controlled position of quantum emitters, surface enhanced two photon photoluminescence assisted by multi-resonant simple plasmonic geometries, and the next generation of quantum emitters for nanophotonics and plasmonics.

The sixth session featured plasmonics vortices. The papers focused on poynting vector analysis of multipolar plasmonic fields.

Session seven was devoted to active control including reconfigurable, metasurfaces for dynamical control of the properties of radiation; dynamic flat optics from plasmonic to all-dielectric metasurface, gate-tunable epsilon-near- 
zero (ENZ) meta-structures, and electrically controlled topological surface plasmon polaritons.

Papers presented in the eighth session related to plasmonic nanolasers based on graphene-insulator-metal platform, and plasmon-enhanced upconversion nanolasers.

Plasmonic materials and nanostructures were discussed in the ninth session. Topics included the development of optimal design of plasmonic metal nanoparticles for practical application, plasmonic nanoantenna for extreme terahertz phenomena, rainbow light trapping in ultrathin plasmonic nanogratings, and direct printing of plasmonic micropatterns of gold and silver nanoparticles via precision photoreduction.

The tenth session focused on thermal plasmonics: temperature-dependent plasmonic properties as a key to high-temperature nanophotonic designs, thermoplasmonics for investigation of microbubble dynamics in degassed water, and photoelectric conversion via plasmonic nanohole arrays.

Papers related to nonlinear photonics were featured in the eleventh session, which involved interfacial second harmonic nonlinearity in resonant nanostructure, polarization generation and manipulation based on nonlinear plasmonic metasurfaces, amplifying conversion efficiencies of SP-enhanced SHG from Ag surface with nonlinear optical polymer films, local fields and resonances for nonlinear metasurfaces, and metallic quantum films and its applications.

The twelfth session was concerned with plasmonic materials and nanostructures: alternative plasmonic materials for better performance in the ultraviolet and visible spectral regions, and low-cost nanofabrication of large-area three-dimensional plasmonic nanostructures using nanospherical-lens lithography and hole-mask lithography.

Session thirteen papers focused on the topic of chiral plasmonics, such as nanoscale chiral valley-light interface and enantio-selective sensing using plasmonic racemic arrays.

Plasmonic sensing was the topic of session fourteen: recent progress in metasurface biosensors for highly efficient fluorescence detection, plasmonic Fano sensors for a singularity point in molecular diagnostics, in vivo detection of microRNA within plants using plasmonic nanosensors, and design of magnetoplasmonic crystal for DC magnetic field sensor. 
The fifteenth session papers involved plasmonic applications including molecular optomechanics in plasmonic nanocavities, and plasmon-enhanced energy transfer via nanostructures.

The sixteenth session was devoted to plasmonic sensing as well such as illuminating bacterial communities with plasmonic nanoantennas, application of a plasmonic chip to sensitive bio-detection and fluorescence microscopic imaging, and plasmonic sensing of hydrogen in Pd nano-hole arrays.

Fundamentals of plasmonics was the topic of the seventeenth session. Papers were presented on tunable Q-factor in dielectric metasurface and Tamm plasmon polaritons, optical critical coupling in nanogap antennas, investigating electromagnetic field enhancements from gold nanostructured arrays for plasmon enhanced fluorescence, and on both plasmonic and Fano resonances in layered metal and dielectric structures.

The final two sessions were concerned with plasmonics applications as well, with topics including self-organized metasurfaces enabling plasmon hybridization, TERspectromicroscopy in the atomistic near-field, and high-speed near-field optical imaging.

\section{Din Ping Tsai Takuo Tanaka}


Proc. of SPIE Vol. 11082 1108201-16

Downloaded From: https://www.spiedigitallibrary.org/conference-proceedings-of-spie on 26 Apr 2023 Terms of Use: https://www.spiedigitallibrary.org/terms-of-use 